\title{
PECUÁRIA, ESPAÇO E RECURSOS NO MATO GROSSO DO SUL - BRASIL
}

\section{LIVESTOCK, SPACE AND RESOURCES IN MATO GROSSO DO SUL - BRAZIL}

\begin{abstract}
Lisandra Pereira Lamoso
Doutora em Geografia Humana pela Universidade de São Paulo Pós-doutorado em Geografia no IGEO da Universidade Federal do Rio de Janeiro Docente na graduação e no mestrado em Geografia da UFGD Bolsista de Produtividade em Pesquisa II do CNPq. lisandralamoso@ufgd.edu.br
\end{abstract}

\section{Resumo}

O Estado de Mato Grosso do Sul tem sua dinâmica produtiva historicamente formada pela pecuária e lavoura de grãos, tendo se integrado ao capitalismo industrial pelas exportações de commodities a partir dos anos sessenta. A pecuária bovina sempre esteve distribuída pelo território, embora ainda concentrada no Pantanal, onde recursos naturais lhe reservam exclusividade no uso do espaço rural. $O$ objetivo desta pesquisa foi compreender características atuais da pecuária bovina utilizando a proposta de combinação de recursos: humanos, técnicos, físicos, de capital e financeiros; além dos conceitos de produtividade e competitividade. Foram utilizados dados secundários extraídos de IBGE, MAPA, EMBRAPA, SEMAGRO, além de revisão bibliográfica. Concluímos que a dinâmica produtiva da pecuária bovina no Mato Grosso do Sul tem sido o resultado de eficiente combinação das vantagens comparativas naturais, tem incorporado tecnologia e com isso alcançado parâmetros de competitividade e produtividade.

Palavras-chave: Pecuária bovina. Agronegócio. Combinação de recursos. Vantagens comparativas naturais.

\begin{abstract}
The State of Mato Grosso do Sul has its productive dynamics historically formed by livestock and grain farming, having integrated to industrial capitalism by commodity exports since the 1960s. Cattle breeding has always been distributed throughout the territory, although it is still concentrated in the Pantanal, where natural resources reserve it exclusivity in the use of rural space. The objective of this research was to understand the current characteristics of cattle breeding using the proposed combination of resources: human, technical, physical, capital and financial; in addition to the concepts of productivity and competitiveness. Secondary data extracted from IBGE, MAPA, EMBRAPA, SEMAGRO were used, besides bibliographic review. The authors concluded that the productive dynamics of cattle breeding in Mato Grosso do Sul has been the result of the efficient combination of natural comparative advantages and has incorporated technology, and with this, has achieved parameters of competitiveness and productivity.
\end{abstract}


Keywords: Bovine livestock. Agribusiness. Combination of resources. Natural comparative advantages.

\section{Introdução}

O Estado de Mato Grosso do Sul, constituído administrativamente em 1979, com a divisão do Estado de Mato Grosso, é bastante conhecido pela produção de commodities agrícolas (grãos como milho e soja). A essas, associam-se a expansão da cana-de-açúcar a partir do início dos anos 2000 (na porção centro-sul) e da silvicultura de eucalipto, que forma o complexo celulose (na porção nordeste). A agroindústria de aves e suínos e a pecuária bovina formam o complexo de proteína animal que compõe o produto interno bruto ligado ao agronegócio. Nesse conjunto, a pecuária é a mais tradicional das atividades, desenvolvida de forma mercantil logo após a Guerra do Paraguai. A atividade tem persistido, disputado espaço soja e a cana. A área plantada da soja, no estado, que era de 1.791.910 hectares em 2009 passou para 2.882.107 hectares em 2019 (IBGE, 2020). A área plantada com cana-de-açúcar, em 2009 foi de 285.993 hectares em 2009 e de 727.753 hectares em 2019 (IBGE, 2020)

No conjunto da produção agropecuária, quando comparado à produção agrícola nacional, os dados do Censo Agropecuário (IBGE, 2018), apresentam Mato Grosso do Sul como $10^{\circ}$ maior produtor de feijão em grãos, $6^{\circ}$ maior de trigo, $5^{\circ}$ maior produtor de soja em grãos, $4^{\circ}$ maior produtor de milho em grãos, cana-de-açúcar e mandioca e $3^{\circ}$ maior rebanho bovino, atrás de Mato Grosso e Minas Gerais e a carne bovina é, também, o terceiro produto mais exportado, após celulose e soja. É sobre a pecuária que nos debruçamos neste texto, com o intuito de compreender como tem se dado a permanência e convivência com as demais dinâmicas produtivas. O que há de novo para além da tradicional pecuária extensiva e como se comporta em termos de competitividade e produtividade.

Os dados foram extraídos de fontes secundárias como o Ministério do Desenvolvimento Indústria e Comércio (MDIC), Instituto Brasileiro de Geografia e Estatística (IBGE), Centro de Estudos Avançados em Economia Aplicada (Cepea), Secretaria de Estado de Meio Ambiente, Desenvolvimento Econômico, Produção e Agricultura Familiar (Semagro), Empresa Brasileira de Pesquisa Agropecuária (Embrapa), bem como revisão bibliográfica. Este texto, além desta Introdução, está 
dividido em três partes. Iniciamos pelo item "Pecuária, Espaço e Recursos", no qual apresentamos, ainda que brevemente, o norte metodológico adotado. Na segunda parte, apresentamos dados sobre a organização da pecuária bovina no Mato Grosso do Sul. Na terceira, informações sobre a inserção da produção no mercado externo, como indicativo de competitividade e produtividade. Nas Considerações Finais, apresentamos uma síntese do potencial de contribuição da análise da atividade como resultado de uma eficiente combinação de recursos, deixando em aberto as possíveis limitações para sua contínua reprodução.

\section{Pecuária, espaço e recursos}

Para compreender a dinâmica produtiva da pecuária bovina no Mato Grosso do Sul, contamos com o aporte teórico dos seguintes autores: Santos $(1990,1996)$, que nos ajuda, com a noção de "rugosidades" a pensar a permanência da pecuária extensiva como persistência de uma divisão internacional do trabalho "manifestada localmente por combinações particulares de capital, das técnicas e do trabalho utilizados" (SANTOS, 1990, p. 138). Sanchéz (1991), que nos ensina sobre os fatores básicos que formam o sistema produtivo, representados por: a) recursos humanos; b) recursos técnicos; c) recursos físicos e d) recursos de capital ou financeiros. Estes recursos podem estar disponíveis e serem utilizados ou não. A ideia é de "combinação de recursos". De forma semelhante, Cholley (1964a, 1964b) afirmava que "[...] os fatos geográficos são essencialmente complexos; eles respondem a convergências, a combinações de fatores" (1951, p. 18). Os fatores a serem combinados na superfície terrestre seriam de três ordens: 1) fatores físicos; 2) fatores bióticos; e 3) fatores humanos. Caberia à geografia encontrar as formas de combinação desses fatores em cada parcela da superfície terrestre e identificar as "ordens" e as "unidades" existentes que derivariam dessas combinações.

“A combinação de recursos humanos, técnicos e físicos configura a capacidade produtiva do trabalho" (SÁNCHEZ, 1991, p.175). Seu desenvolvimento define o desenvolvimento das forças produtivas e a combinação de recursos humanos e capital deriva para relações sociais de produção, segundo o mesmo autor. Para Mato Grosso do Sul, podemos afirmar que houve um grau eficiente de combinação desses quatro recursos, a saber: 
a) Humanos - Na pecuária extensiva, pouco se alterou a necessidade de mãode-obra ao longo dos anos. Em termos de força de trabalho, o que ocorre, além das atividades práticas, para as quais se exige experiência de manejo, é a necessidade do emprego de qualificação (veterinários, técnicos agrícolas, zootecnistas). Há oferta desses profissionais no mercado e muitos são filhos de pecuaristas, que se diplomam nas carreiras voltadas ao campo. À medida em que os núcleos urbanos foram se formando, residir na área rural não é mais um empecilho embora seja cada vez mais difícil encontrar reposição da mão de obra que foi envelhecendo e levando consigo o know how da criação. Uma particularidade é dada pela região do Pantanal, ou pelos Pantanais, já que diversos. Nesta região há um distanciamento físico dos núcleos urbanos (Corumbá, Ladário, Porto Murtinho, Aquidauana, Anastácio) tanto em quilômetros quanto pelas condições naturais que existem na época das cheias, pois em certas sedes de fazendas, só é possível chegar de avião.

b) Técnicos - A pecuária extensiva tem técnicas de manejo que já foram apropriadas pelos capatazes e pelos chamados peões. As demais etapas, quando semiintensiva e intensiva, exigem conhecimento formal quanto à composição nutricional suplementar, técnicas de inseminação, melhoramento genético, ganho de peso precoce, inseminação artificial, acompanhamento de cotação em redes de comercialização, participação em leilões virtuais, logística. A Embrapa Gado de Corte, direta ação estatal, tem papel importante nas pesquisas e no aperfeiçoamento da produção, disponibilizando estratégias de aumento da rentabilidade para o rebanho.

c) Físicos - Os fatores físicos dizem respeito às condições favoráveis de clima, topografia, solo, rede hidrográfica. No Mato Grosso do Sul, 60\% da área está ocupada por pastagens (18.439.835,00 ha), 12\% lavouras (3.629.534,00 ha), 24\% matas e florestas (7.345.951,00 ha) e 4\% outros usos (1.133.859,00 ha), segundo dados do último Censo Agropecuário (IBGE, 2017). Os 60\% de pastagens, estão divididos em $71 \%$ de pastagens plantadas em boas condições (13.065.924 ha), 27\% são pastagens naturais (4.913.017 ha) e apenas 2\% são pastagens plantadas em más condições (460.894 ha). Este é um recurso natural importante pois possibilita a criação do "boi a pasto". O boi a pasto alimenta-se predominantemente da vegetação, pode ser da pastagem natural ou plantada. Esse animal é conhecido, também, como "boi verde", o que tem um apelo de marketing, de alimento mais saudável. Apesar de coexistirem os três sistemas de produção: extensivo, semi-intensivo e intensivo, predomina a produção extensiva. O semi-intensivo 
trata o boi com mais emprego de tecnologia, dando alimentação diferenciada e realizando manejo de pastagem. O intensivo implica em elevado nível sanitário e reprodutivo, alimentação oferecida na modalidade de confinamento, para padronizar a oferta do produto no mercado e otimizar o ganho de peso. A pecuária extensiva é a tradicional, com pouco emprego de mão-de-obra e cuidados básicos de manejo, como vacinação obrigatória, vale-se das pastagens naturais como um nutriente de baixo custo, além da disponibilidade de águas também ser um elemento que favorece a renda do produtor, embora pareça algo muito "natural” e não contabilizado. Água, sol, solo, topografia, pastagem natural, são fatores que compõe a atividade pecuária, pelas condições que apresentam, consideramos como parte das vantagens comparativas naturais. A estrutura fundiária que possibilita a criação do boi a pasto é uma condição histórica, resultado de relações políticas e de poder não alteradas ao longo do tempo. O índice Gini para Mato Grosso do Sul foi de 0,805 no ano de 2003 (GIRARDI, 2008), sem alterações estruturais desde então. Áreas maiores possibilitam rentabilidade e competitividade ao disponibilizar alimentação bovina via pastagens naturais ou até artificiais, sem os custos mais elevados de manejo, como é o caso do confinamento. Nenhum desses fatores sofre com taxas de câmbio ou com a macroeconomia internacional, há uma estabilidade nesta atividade econômica. São fatores disponíveis nesta fração do território. Há uma combinação de fatores ou recursos favoráveis à constituição da atividade no Mato Grosso do Sul que tem persistido ao longo do tempo, desde a expansão da fronteira agrícola do sudeste para o antigo sul de Mato Grosso, quando foi se estabelecendo uma extensão do agropastoril do oeste de São Paulo.

No Pantanal, em particular, não há competição de área com outra atividade agropecuária. O próprio meio não possibilita plantações de grãos, silvicultura e cana estão restringidas pelas normas ambientais. A área rural é toda para pecuária, com exceção da Morraria do Urucum, de onde se extrai ferro e manganês. No Pantanal, os fatores físicos (clima, topografia, água, pastagem natural) e biológicos (rebanhos) foram mais decisivos que os fatores humanos.

d) Recursos de capital e financeiros - A pecuária de corte é uma atividade rentável, dados que seus principais fatores de produção estão ancorados em vantagens comparativas naturais e na estrutura fundiária que permite o uso extensivo do território. Há, porém, casos diversos: pecuaristas, tradicionais proprietários de terras que estão há muitos anos na atividade e repassando por herança, o negócio aos sucessores, com mínima 
ou nenhuma dependência de crédito externo, se autofinanciam. E agropecuárias de grande porte, que profissionalizaram toda gestão e desenvolvem projetos para captação de recursos. Há que se considerar, também, linhas de crédito disponibilizadas por bancos de fomento (notadamente BNDES) que possibilitaram a instalação, ampliação e aquisições na indústria frigorífica, ampliando a capacidade de abate, com direta participação do Estado.

Além da combinação de fatores, contamos com Bernardes e Castillo (2019) e Castillo (2015), leituras que contamos para problematizar as noções de competitividade e produtividade. Segundo Castillo (2015, p.105), competitividade é, por um lado, um parâmetro mundializado de desempenho de agentes econômicos e de qualidade e custo dos produtos", e também,

Uma qualidade do espaço geográfico, considerando que as regiões e os territórios podem ser mais ou menos adequados às exigências dos mercados internacionais. A competitividade territorial ou regional resulta da rara combinação entre fatores materiais (naturais e/ou técnicos) e imateriais de produção e de circulação/distribuição de um dado produto ou cadeia produtiva, numa dada fração do espaço geográfico. (CASTILLO, 2015, p.105).

Produtividade é "uma qualidade que se atribui a agente ou a um objeto, ou, em termos marxistas, à terra, ao trabalho e ao capital, de forma absoluta e independente de outros agentes e objetos" (BERNARDES e CASTILLO, 2019, p.11). A produtividade pode ser representada pelo ganho de peso em dias, ou pela quantidade de arroba produzida por hectares. São medidas objetivas. Colocam o espaço como instância de análise, nos fazendo superar ou complementar as análises econômicas que são baseadas nas leituras de volumes de produção, valores de exportação, competência técnica, como se a atividade da pecuária (e muitas outras, principalmente na agropecuária), não mantivessem forte ancoragem nos recursos espaciais, na oferta que o território disponibiliza, que em Economia chamamos de "vantagens comparativas naturais".

\section{Pecuária, espaço e recursos}

Nos últimos quarenta anos, houve uma expansão considerável do rebanho bovino pelo território brasileiro, apenas trinta municípios não possuem bovinos. Na Figura 1, vemos a representação desta expansão pela mancha vermelha que cobre o estado de Mato Grosso do Sul e avança em direção aos municípios da região Norte, área bastante sensível 
em termos socioambientais, inclusive foco do debate atual sobre aumento do desmatamento e da ocorrência de queimadas.

Figura 1 - BRASIL - Expansão do rebanho bovino (1978-2018)
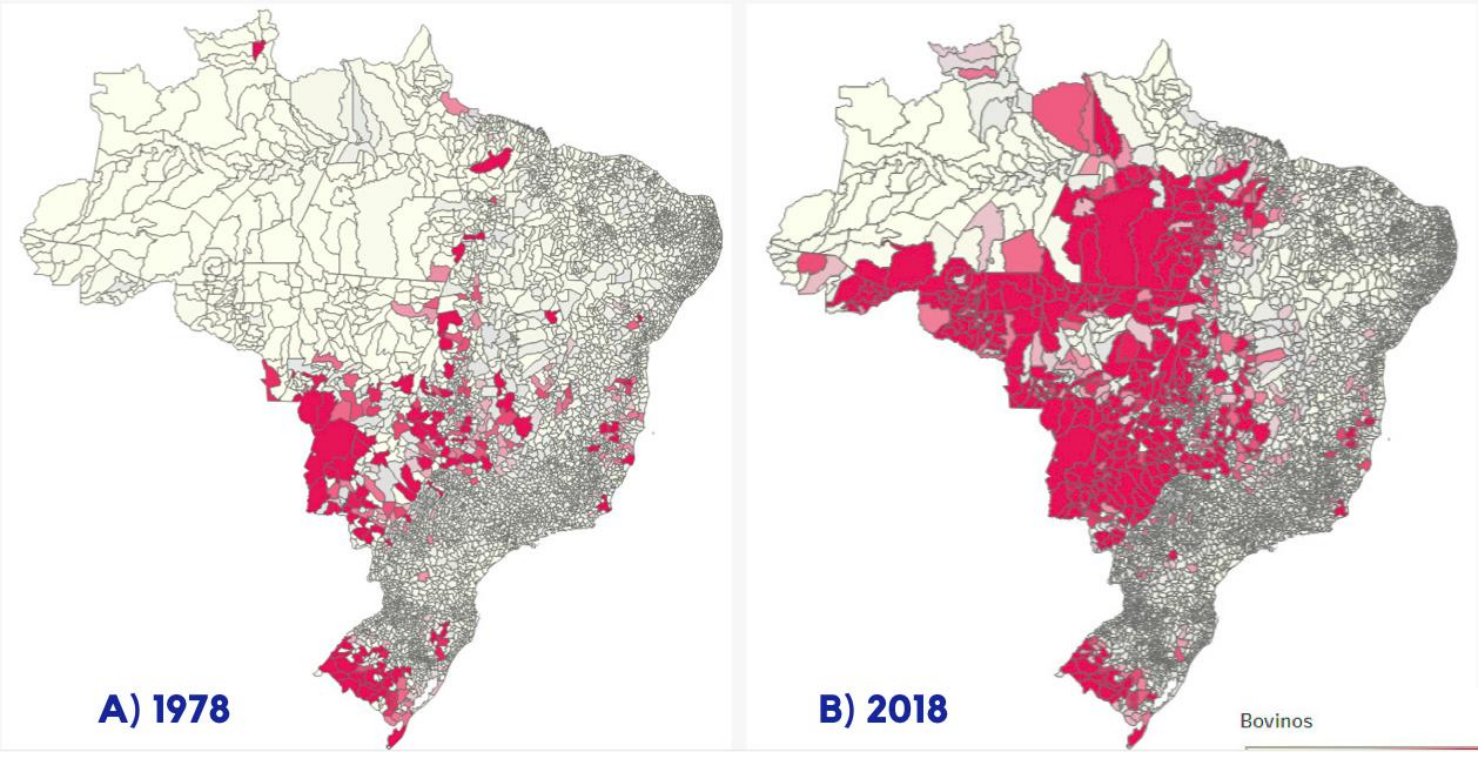

Fonte: Boletim CiCarne/Embrapa.

No próximo item, discutiremos algumas informações gerais sobre a pecuária bovina e dados particulares para Mato Grosso do Sul. A pecuária das Zonas Tropicais do globo, pelas condições físicas (temperatura, quantidade e intensidade luminosa, umidade) apresenta maior diversidade de plantas. A atividade da pecuária se divide, sinteticamente, em três processos: cria, recria e engorda. No Mato Grosso do Sul (antigo sul de Mato Grosso), se realizava a cria, tradicional na porção mais interior do Brasil Central Pecuário (BENITEZ, 2000). Os recriadores ocupavam, principalmente, a região do Triângulo Mineiro e a engorda (invernistas), ocupavam "as porções do Oeste de São Paulo e as regiões de Montes Claros, Teófilo Otoni e Governador Valadares" (BENITEZ, 2000, p. 11). Com o passar dos anos, as três etapas já podem ser encontradas no Mato Grosso do Sul, inclusive o abate e frigorificação, feitas por importantes corporações transnacionais, de capital privado nacional. No Pantanal, a Empresa Marinho de Agropecuária do Pantanal Ltda (EMA), Fazenda Ema realiza o ciclo completo, com a cria na Região Pantanal (Paiaguás, Nhecolândia e Jacadigo), recria (Jacadigo) e engorda (Serra de Corumbá - Albuquerque e Maria Coelho). Inclusive alcançando a frigorificação, com a implantação do Frigorífico Marinho (Frima), frigorífico que abate produção própria. 
Estudos sobre a pecuária no Mato Grosso do Sul já foram desenvolvidos por vários pesquisadores, dada sua expressão econômica e a sua participação na formação socioespacial regional. Há trabalhos de Mamigonian (1976 e 1986), Bertholi (2006); Paz (2009), Galera (2011), Silvestre e Guerrini (2014), Lima (2018), para citar alguns. Em 2017, os dados do último censo agropecuário confirmaram uma tendência já de alguns anos, de redução do tamanho do rebanho bovino. Em 2010, eram 22.354.077 cabeças, que passaram para 21.003.830 em 2014 e para 20.896.700 no ano de 2018. (Ver Figura 2). Certa oscilação decorre de questões típicas de mercado, como preços e sua regulação via abate de fêmeas, mas é uma redução que chama a atenção pela expressão dos números.

A redução não foi uma tendência macrorregional, pois no Centro-oeste, o estado de Mato Grosso apresentou um aumento de mais de $5 \%$ e em Goiás, de 7,4\%, no período de 2010 a 2016. No país, o maior crescimento do rebanho tem se dado na região Norte, nos estados de Rondônia e Pará, não por acaso, com aumento do índice de desmatamento e focos de queimadas nos anos de 2018 e 2019.

No Mato Grosso do Sul, a distribuição espacial está concentrada em duas microrregiões, do Pantanal e de Três Lagoas (Ver Figura 3). Na porção meridional, na Região da Grande Dourados, o espaço rural é mais ocupado pela lavoura, com recente expansão da cana-de-açúcar.

Figura 2 - Mato Grosso do Sul - Evolução do rebanho bovino

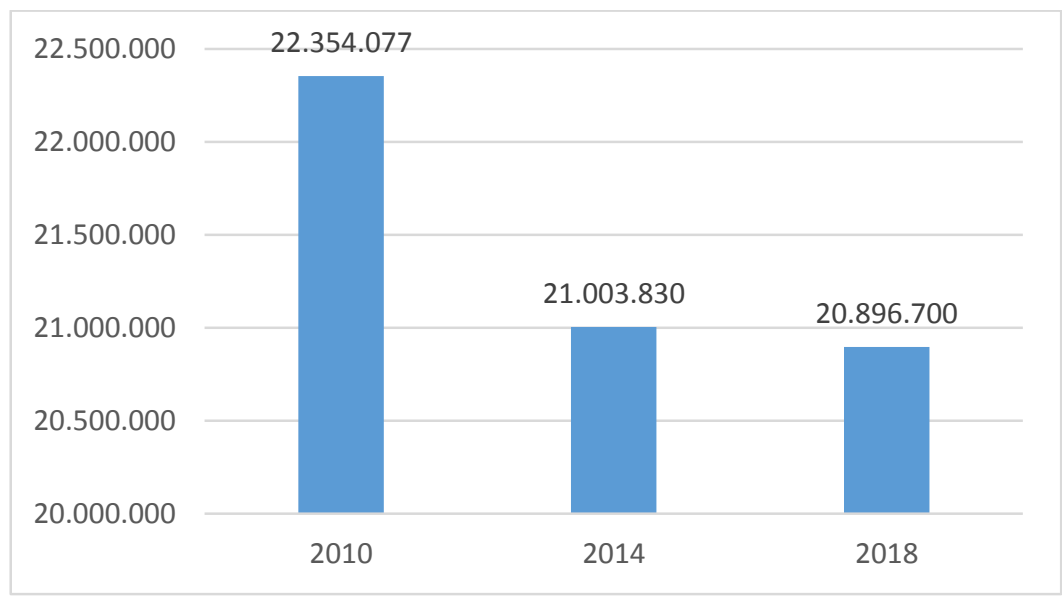

Fonte: MAPA.

Org.: pela autora.

A mancha mais clara no mapa (Ver Figura 3) é justamente a representação do espaço de realização do processo de diversificação mais intenso do estado, onde a 
pastagem disputa área com cana e soja, a primeira, predominante na forma de arrendamentos e a segunda, com o peso do preço do produto em função da demanda internacional. Na porção meridional, espaço mais diversificado, resultou da combinação de fatores sócio-econômico culturais que foram proporcionadas pela implantação da Colônia Nacional Agrícola de Dourados, projeto de colonização oficial do Governo Vargas, de 1943. Nesta porção, há registros de suinocultura, avicultura, helicicultura, piscicultura, produção de hortifrutícolas e outras de menor porte. Sobre a suinocultura, Lamoso et al. (1996) e Lamoso e Silva (1997) apontavam como ocorria o trabalho de produtores familiares na condição de integrados à empresa Seara Alimentos.

A suinocultura teve início como atividade para consumo próprio foi ganhando escala, utilizando a disponibilidade de mão de obra (familiar, no início, e predominantemente assalariada, quando a produção foi integrada à indústria). Favorecida pela oferta de grãos que compuseram a ração, da mesma forma que ocorria com a avicultura.

A sericicultura (criação do bicho da seda), desenvolvida no município de Glória de Dourados e Juti. Outra atividade, a helicicultura (criação de caracol) também se desenvolvia de forma incipiente e foi objeto de estudos de Manfré et al. (1999). Nesta não houve progresso em direção ao aumento da produção devido a problemas com a organização do mercado final. A pesca amadora nos rios regionais caminhou para atividade de lazer comercial, na forma de pesqueiros e pesque-pague e, aos poucos, para a atividade da piscicultura comercial, tema pesquisado por Faria et. al. (1999). Atualmente, trata-se de uma diversificação econômica importante, com expressiva produção de tilápia para exportação. Nesta porção meridional, está a menor concentração de cabeças.

Os cinco municípios com maior rebanho são, por ordem decrescente, Corumbá (1.927.002 cabeças), Ribas do Rio Pardo (1.085.497), Aquidauana (794.825), Porto Murtinho (647.006) e Santa Rita do Pardo (544.691) (IBGE, 2018). 
Figura 3 - Mato Grosso do Sul - Efetivo do rebanho bovino - 2017*

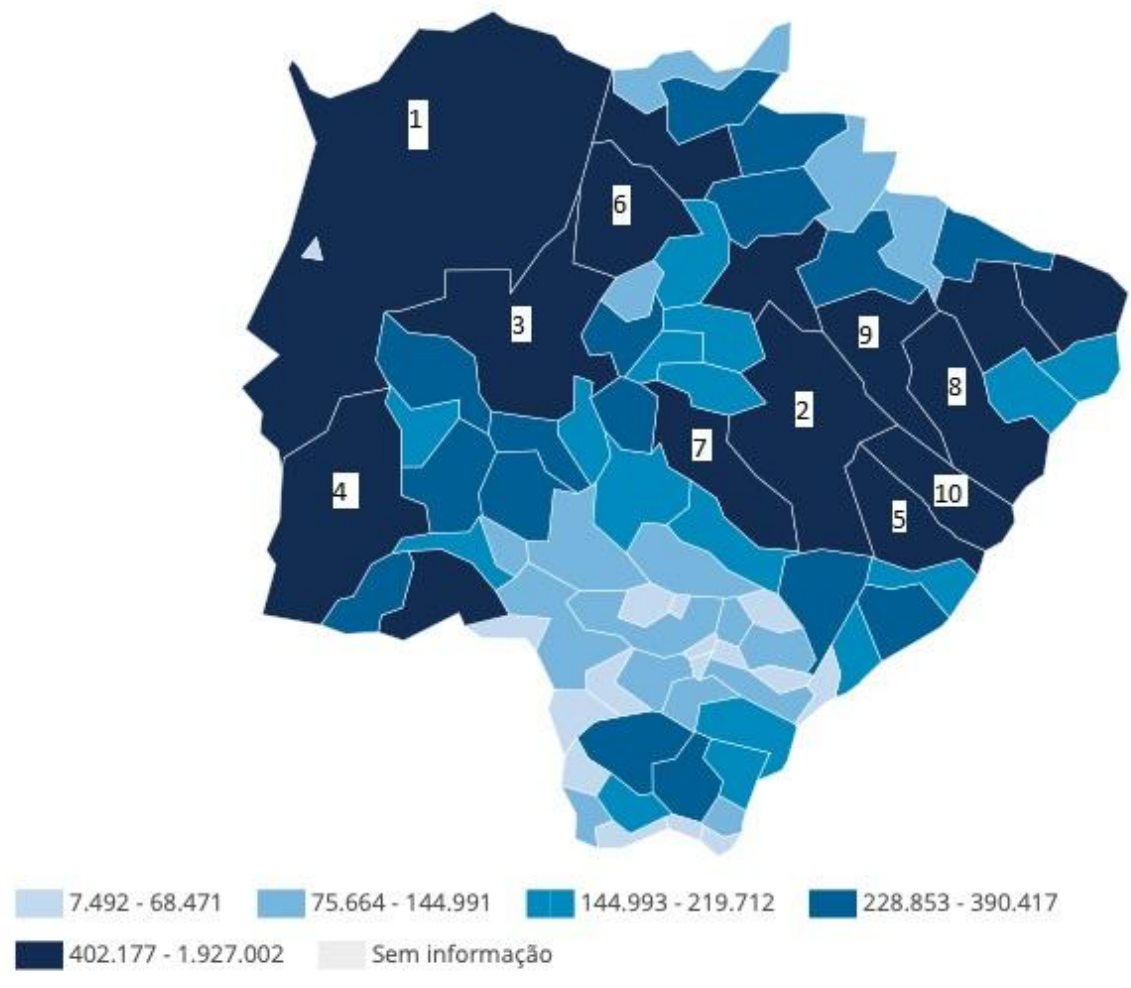

*Municípios com maior rebanho bovino conforme listado na Figura 4. Fonte: IBGE/Censo Agropecuário.

Figura 4 - Mato Grosso do Sul - Bovinos nos municípios de maior rebanho - 2017.
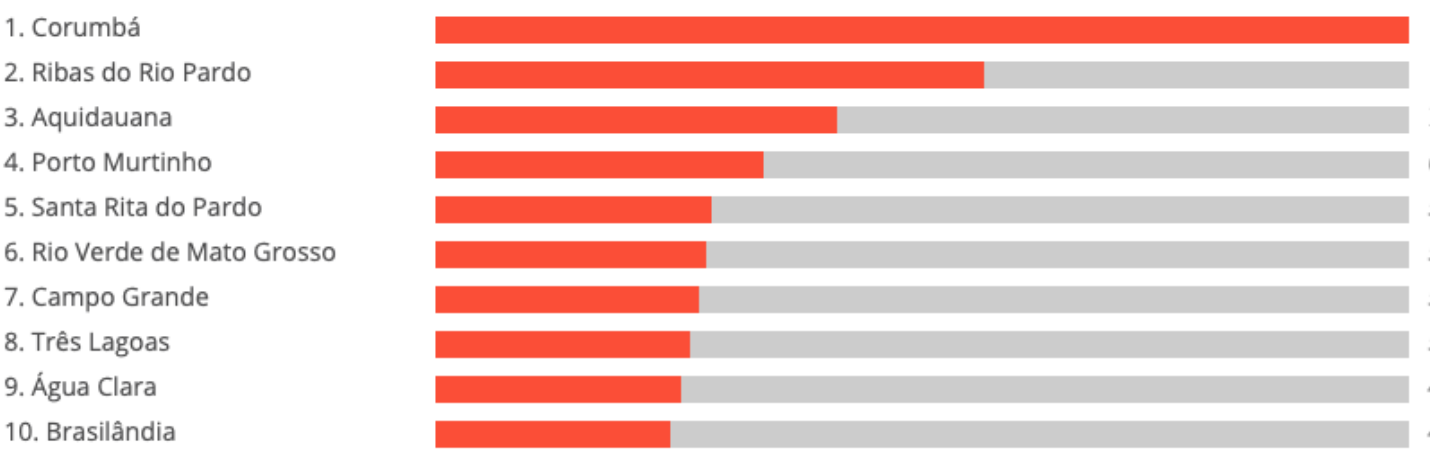

Fonte: IBGE/Censo Agropecuário.

No Pantanal, a pecuária é privilegiada pelos recursos físicos, dada a baixa aptidão das terras para o cultivo de grãos e sua localização geográfica distante dos principais mercados consumidores, além da dificuldade logística para outros tipos de mercadorias. O gado é uma mercadoria que se desloca no meio mesmo sem a presença de veículos de transporte. A falta de competição torna esta atividade estável, no pleno uso da combinação 
de fatores. A pecuária no estado, é um subconjunto da pecuária nacional, que se está assentada em propriedades extensas, resultado do histórico de concentração da estrutura fundiária, com isso pode contar com a oferta natural de pastagens.

Como resultado da combinação de fatores, além de condições macro de mercado consumidor e da conjuntura econômica nacional, a pecuária permanece como atividade rentável, que apresenta aumento do valor bruto da produção, apesar da redução do rebanho (Ver Figura 5), Quanto ao mercado, a melhora da renda ocorrida no período 2006 a 2016, refletiu no aumento do consumo interno. A carne vermelha é uma proteína cara, cujo consumo sofre concorrência com o frango e o suíno. Em média, o brasileiro consome $23 \mathrm{~kg}$ de carne/ano e há espaço para expansão, sempre com dependência do poder aquisitivo, no caso do mercado interno.

A redução do rebanho foi seguida do aumento do preço da arroba, que atingiu níveis de alta histórica no ano de 2018, em todo país, bem como no mercado regional. Em 2018, o preço da arroba alcançou 197 reais $^{1}$ (Ver Figura 6). Isso aponta, a nosso ver, que a pecuária tem uma estabilidade no Mato Grosso do Sul, mesmo quando compete em área e preço com a lavoura (fora do Pantanal). Os ganhos estimulam reinvestimento na atividade. As vantagens comparativas naturais também funcionam para a confirmação de sua consolidação e há um ciclo próprio que regula a oferta do produto.

Figura 5 - Mato Grosso do Sul - Valor bruto da produção de bovinos (em reais)

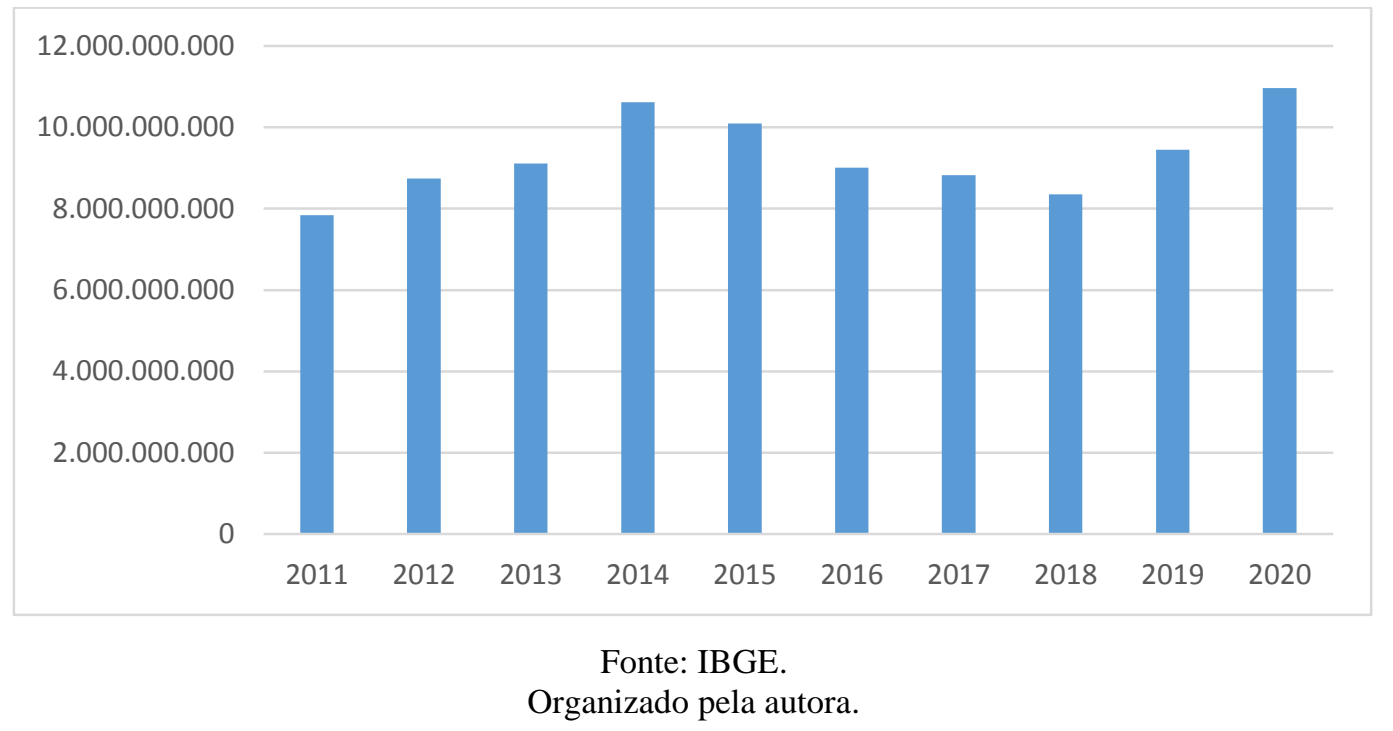

\footnotetext{
${ }^{1}$ Na praça de Dourados-MS, a arroba estava em R \$175,50 na data de 12 de maio/2020, segundo dados da Scot Consultoria, disponível em https://www.scotconsultoria.com.br/cotacoes/boi-gordo/
} 
Figura 6 - Brasil - Preço médio da arroba do boi gordo

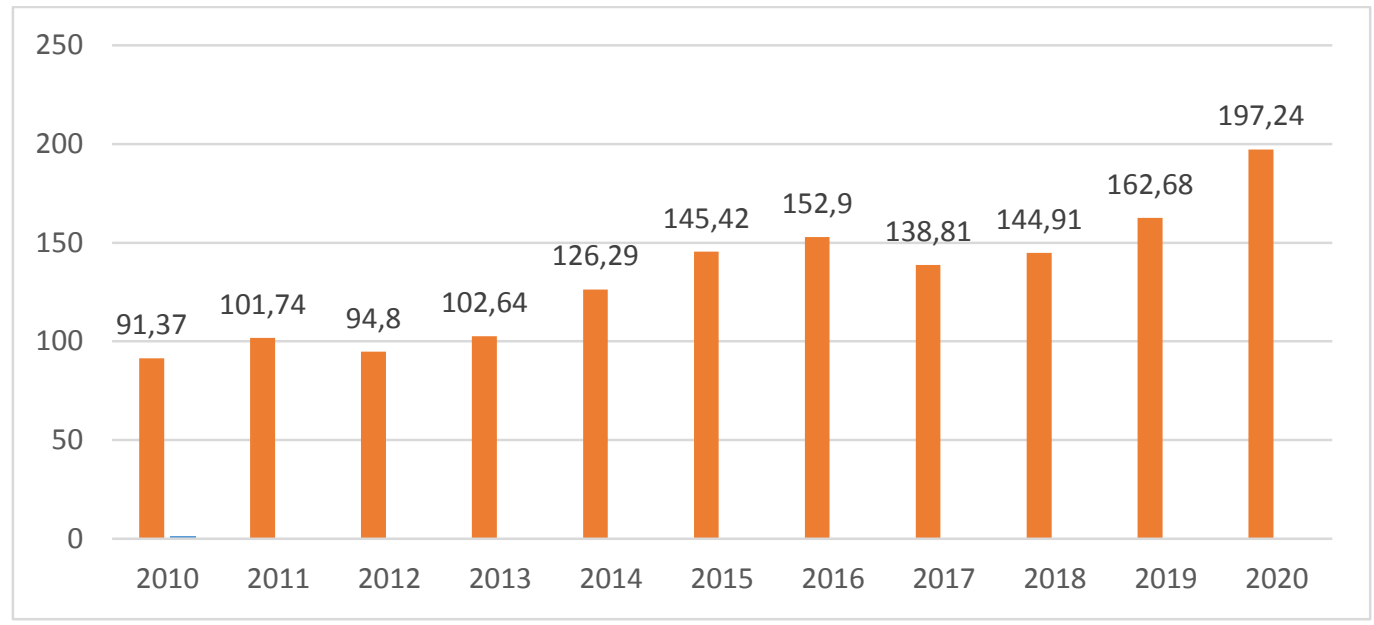

Fonte: CEPEA/B3

Os criadores administram algumas vantagens frente aos demais produtores de proteína animal, pois conseguem controlar preços de médio prazo ao aumentarem o abate de fêmeas e reduzirem o plantel. Podemos observar nas Figura 6 e 7, uma relação no período de 2010 a 2016, de redução do rebanho com aumento do preço da arroba.

Figura 7 - Mato Grosso do Sul - Evolução do rebanho bovino e do abate de reses

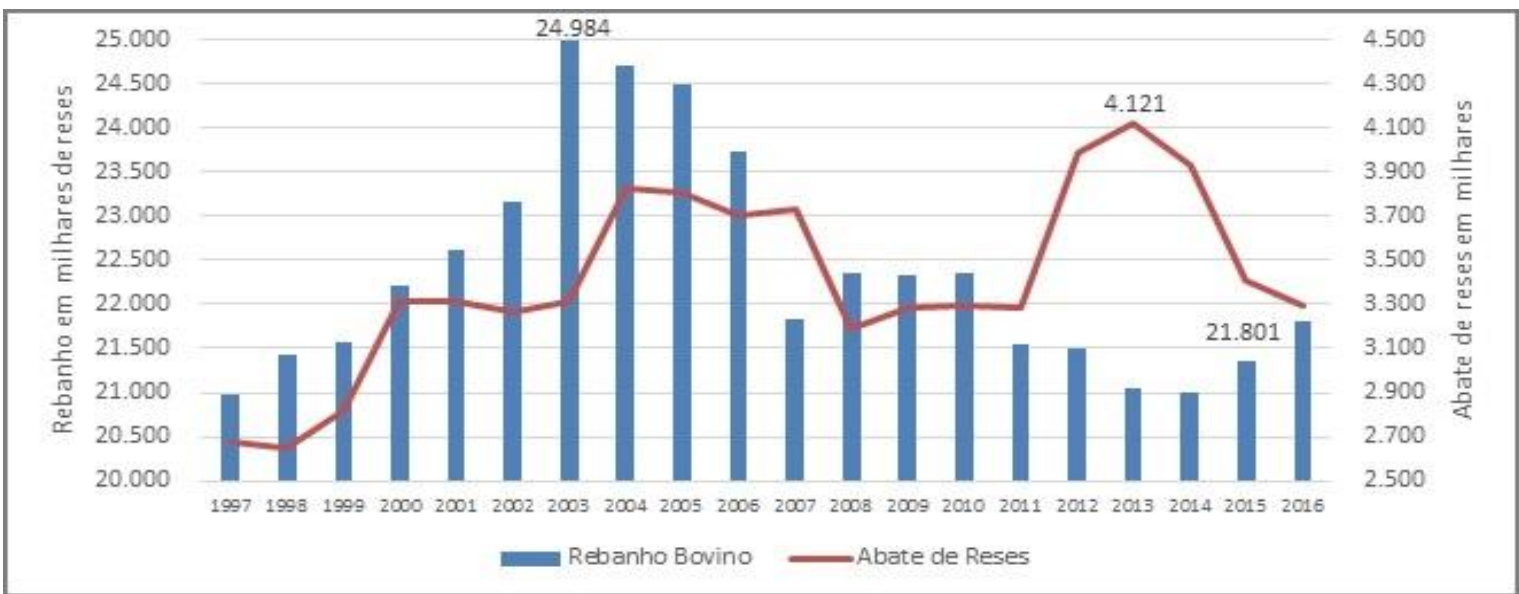

Fonte: Semagro, 2020.

A atividade tem uma sazonalidade de preços e tamanho do rebanho característica do ciclo tradicional da pecuária, conforma podemos observar na Figura 8. 
Figura 8 - Ciclo da Pecuária

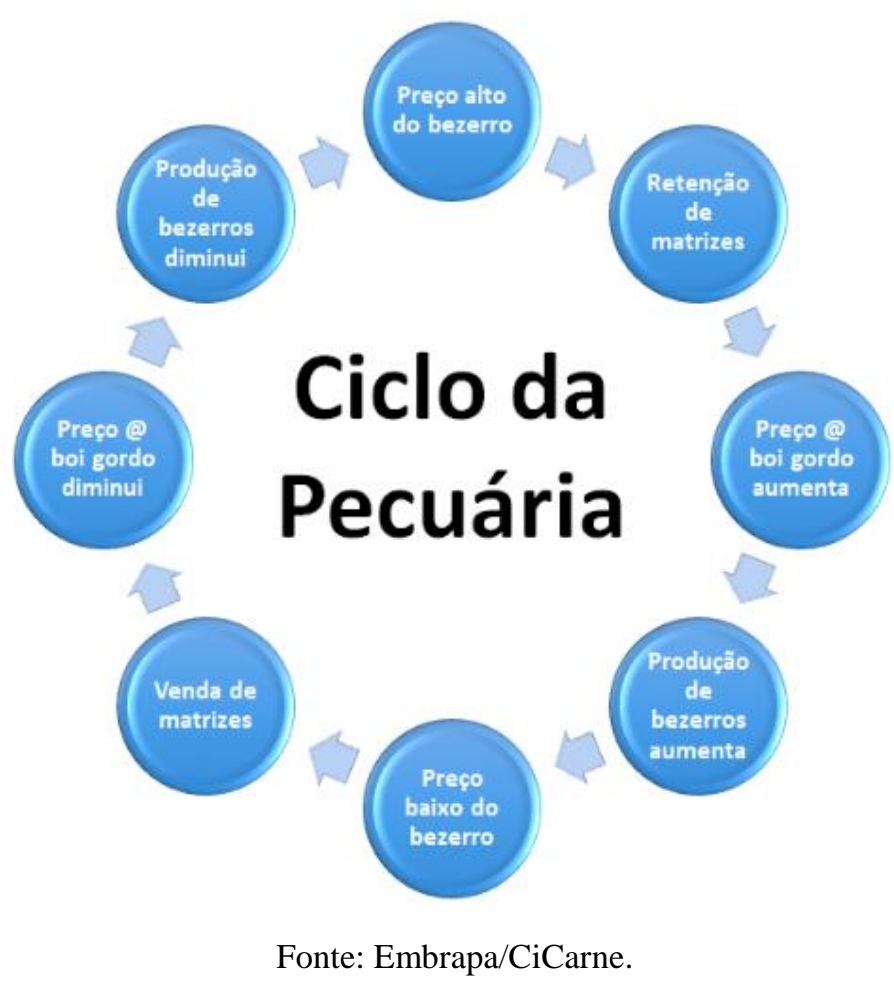

Sobre comércio, competitividade e produtividade

Para atingir o mercado internacional, a mercadoria deve reunir condições de, basicamente, qualidade e preço. Atingindo os dois critérios, a carne bovina é o terceiro produto mais exportado, em valor, do estado, representa $11 \%$, enquanto soja $35 \%$ e celulose 32\%. (MDIC, 2019). Embora fique em maior evidência os frigoríficos exportadores, como o JBS e Minerva, há uma rede de frigoríficos que abatem para o mercado interno, como demonstra a Figura 9, publicada na dissertação de Lima (2018). Há uma oferta de carne fresca ou refrigerada, que chega ao consumidor regional através dos açougues, supermercados. Parte da competitividade, foi obtida pela criação e aperfeiçoamento dos serviços de inspeção sanitária. Na Figura 9, observamos o alcance dos referidos serviços nos municípios do estado. 
Figura 9 - Mato Grosso do Sul - Frigoríficos de Inspeção Estadual e Federal - 2016.

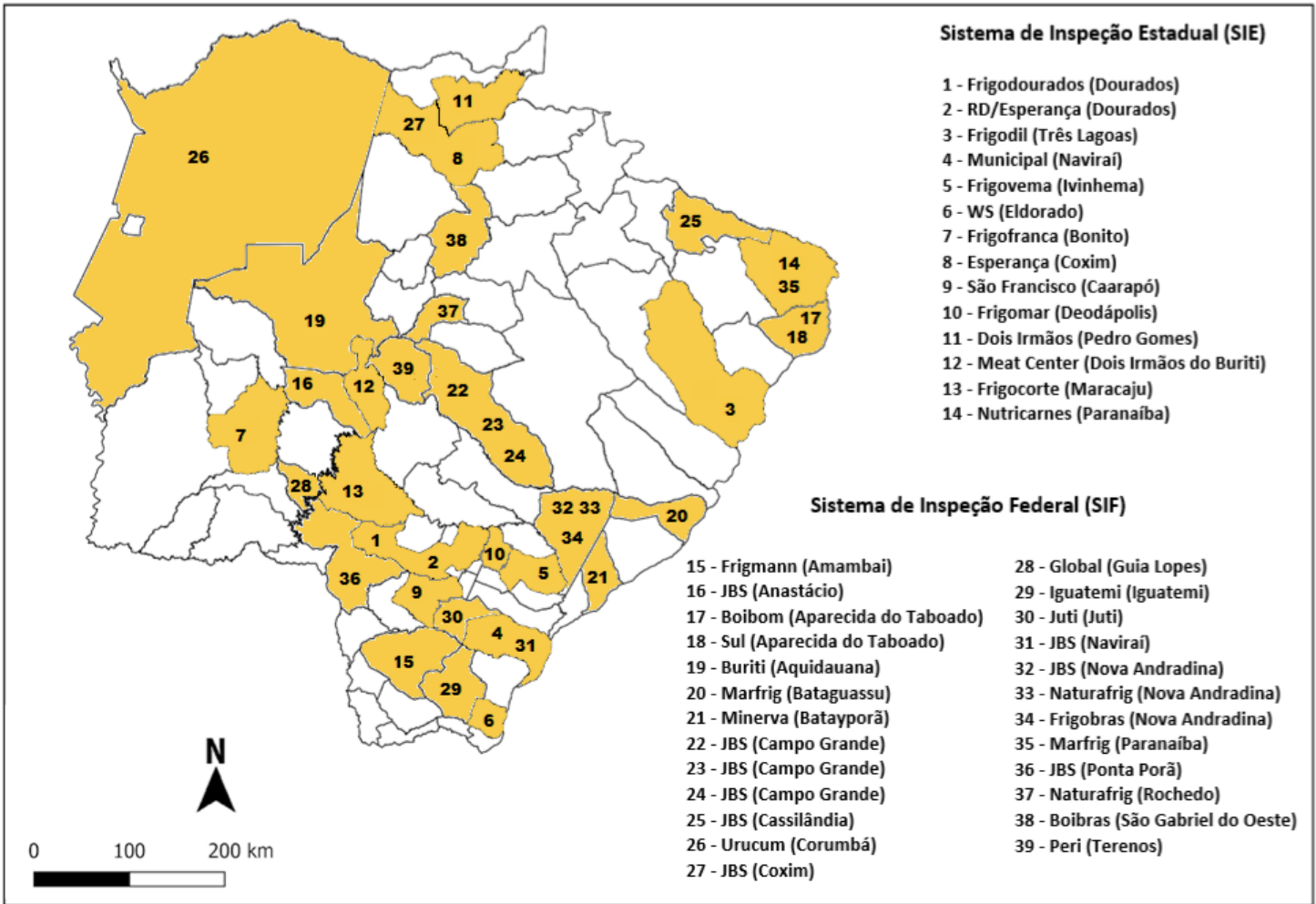

Fonte: Lima, 2018.

O preço varia, em função dos períodos de safra/entressafra, condições de demanda do mercado externo. Foi notável o aumento da oferta de carne congelada ou embalada à vácuo quando o mercado externo se retraiu por causa de apuração de irregularidades na comercialização da carne, conhecida como "Operação Carne Fraca". A oferta para o mercado interno é robusta, embora oscile em função da conjuntura econômica, que interfere no poder aquisitivo do consumidor final. Como a carne alcança o mercado externo, tendo atingido valores na média de 400 milhões de dólares só de carne congelada (MDIC, 2019), admitimos que a carne bovina sul-matogrossense é competitiva. Consideramos como competitiva, a conceituação apresentada por Bernardes e Castillo (2019) e Castillo (2015).

A pecuária do estado está competitiva e se aproveita da combinação de fatores, já comentados, para sua produtividade. Sempre tomando o cuidado de registrar que a competitividade (já que alcança mercados na União Européia, Rússia, Hong Kong) é influenciada pela taxa de câmbio e pelo mercado que demanda o boi verde, criado a pasto. Em 2028, alcançou 339 milhões de dólares (FOB) nas exportações de carnes desossadas de bovino congeladas e 208 milhões de dólares (FOB) em carnes desossadas de bovino, 
frescas ou refrigeradas. Ainda com relação à competitividade, há um dado mais recente, sobre as exportações de animais vivos desde o ano de 2013. Segundo o MDIC (2019), em 2018, no valor de 331.479,00 dólares (FOB).

Figura 10 - BRASIL - Produtividade de carcaças (em kg) por número de abates e por tamanho do rebanho

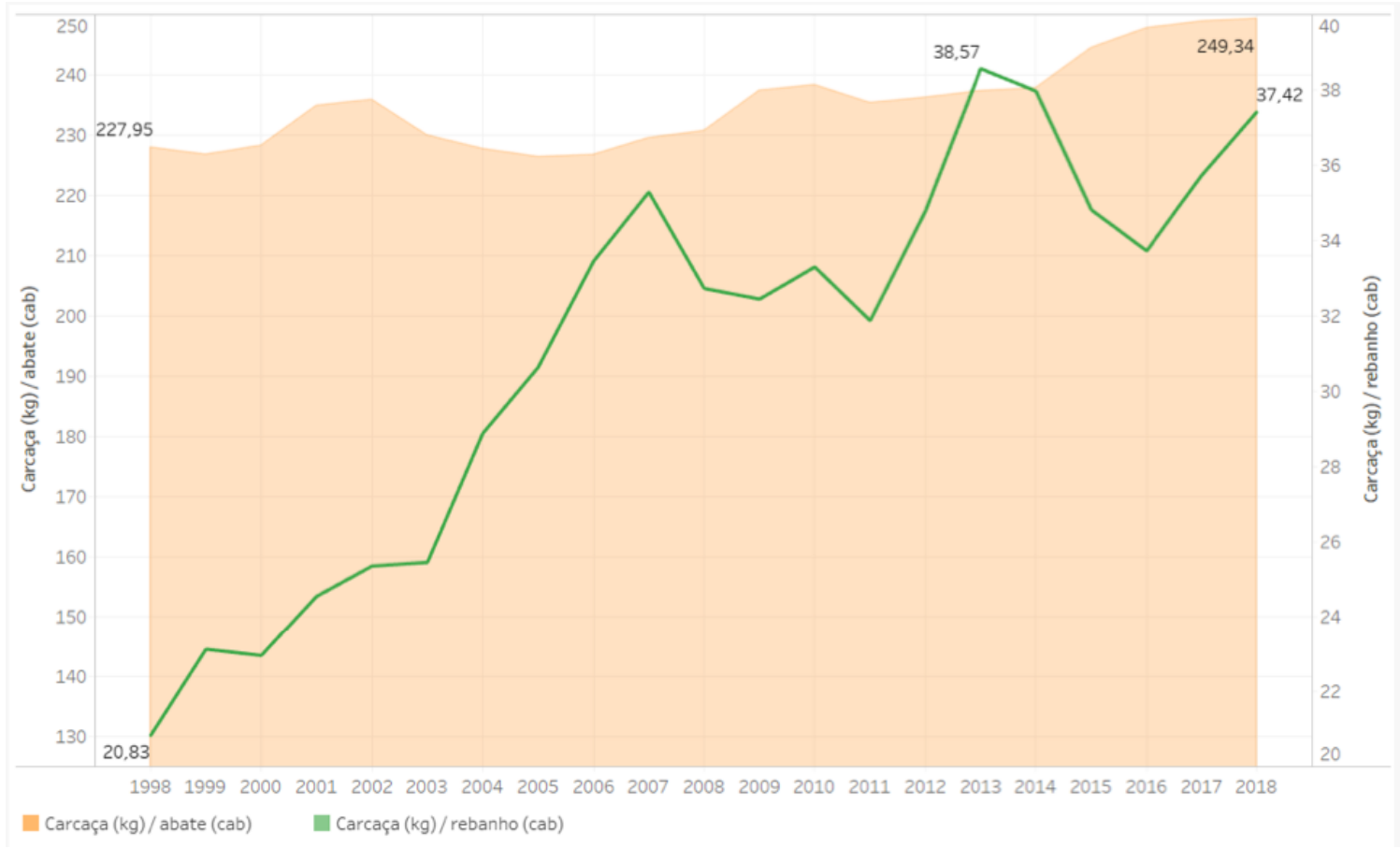

Fonte: EMBRAPA/BOLETIM CICARNE, 2020.

Essas exportações de animal vivo representam venda de animal de genética melhorada. O Paraguai é um mercado que está investindo na genética de formação do seu rebanho e, tanto Mato Grosso do Sul, como Brasil em geral, já possuem décadas de acúmulo nesse processo. Para isso, houve revisão do Certificado Veterinário Internacional, que regula normas para comércio de animais vivos com segurança sanitária.

Embora as exportações sejam ressaltadas pela entrada de dólares nas contas nacionais, há um efeito a ser desconsiderado que é o abastecimento do mercado interno. O boi é bastante segmentado e pode oferecer proteína para várias faixas de preço. Há carnes mais baratas, como a costela, ou subprodutos que podem compor a dieta com elevado teor proteico. A culinária regional elaborara um prato conhecido como "puchero", comida de origem espanhola, adaptada à cozinha paraguaia, muito comum no 
Mato Grosso do Sul. É produzida com músculo e tutano do cozimento dos ossos. A carne chega ao consumidor final através da rede de frigoríficos instalada em vários municípios, com bastante capilaridade.

A busca pelo aumento da produtividade está em curso através de várias estratégias que procuram agregar elementos às já dadas vantagens comparativas naturais. O sistema de confinamento ainda é incipiente, mas está aumentando ano a ano. Segundo a Associação Nacional de Pecuária Intensiva (Assocon), no ano de 2018 o Mato Grosso do Sul registrou 408,4 mil animais confinados, com aumento de 5,5\% em relação ao ano de 2017. Trocas de experiências e demonstrações de práticas de campo são regularmente apresentadas em diversos eventos do setor. Sobre confinamento, o estado sedia anualmente o encontro da Confinar que, entre várias iniciativas, auxilia na disseminação do conceito chamado 7.7.7, que consiste em engordar o boi 7 arrobas na desmama, 7 arrobas na recria e 7 arrobas na engorda, com resultado final de abate com 21 arrobas até os 24 meses de vida, o que geraria uma economia de até 30\% para o produtor. Tecnologias de abate precoce já foram há muitos anos adotadas na suinocultura e avicultura. Como o bovino é de grande porte, ciclo reprodutivo mais demorado que se comparado a aves ou suínos, o melhoramento genético ocorre em outra escala temporal. Além das características físicas, a atividade está assentada na oferta de terras e na lucratividade que vinha sendo obtida com as formas tradicionais de engorda, isso retardou (se comparado aos dois animais, aves e suínos) a aceleração da incorporação de tecnologia.

Nesse contexto, a atividade também tem aberto oportunidades para a expansão da prestação de serviços qualificados que ocorrem no campo de aplicativos e pacotes de software para controle da produtividade. A empresa Beeftech, com sede em Campo Grande, criada em 2012, anuncia serviços de tecnologia em agropecuária. São pacotes personalizados de acordo com o perfil do cliente, que pode conter software de controle para formulação de dietas para cada fase e categoria, acompanhamento técnico, auxílio na compra de produtos e treinamento de mão de obra, projetos de confinamento, ferramentas para ajustar logística de carga e trato, análise de informações zootécnicas e financeiras por lote durante o confinamento e após o abate, entre diversos outros (http://beeftec.com.br). (Ver Figura 11). 
Figura 11 - Propaganda da empresa Beeftec - menu de serviços.

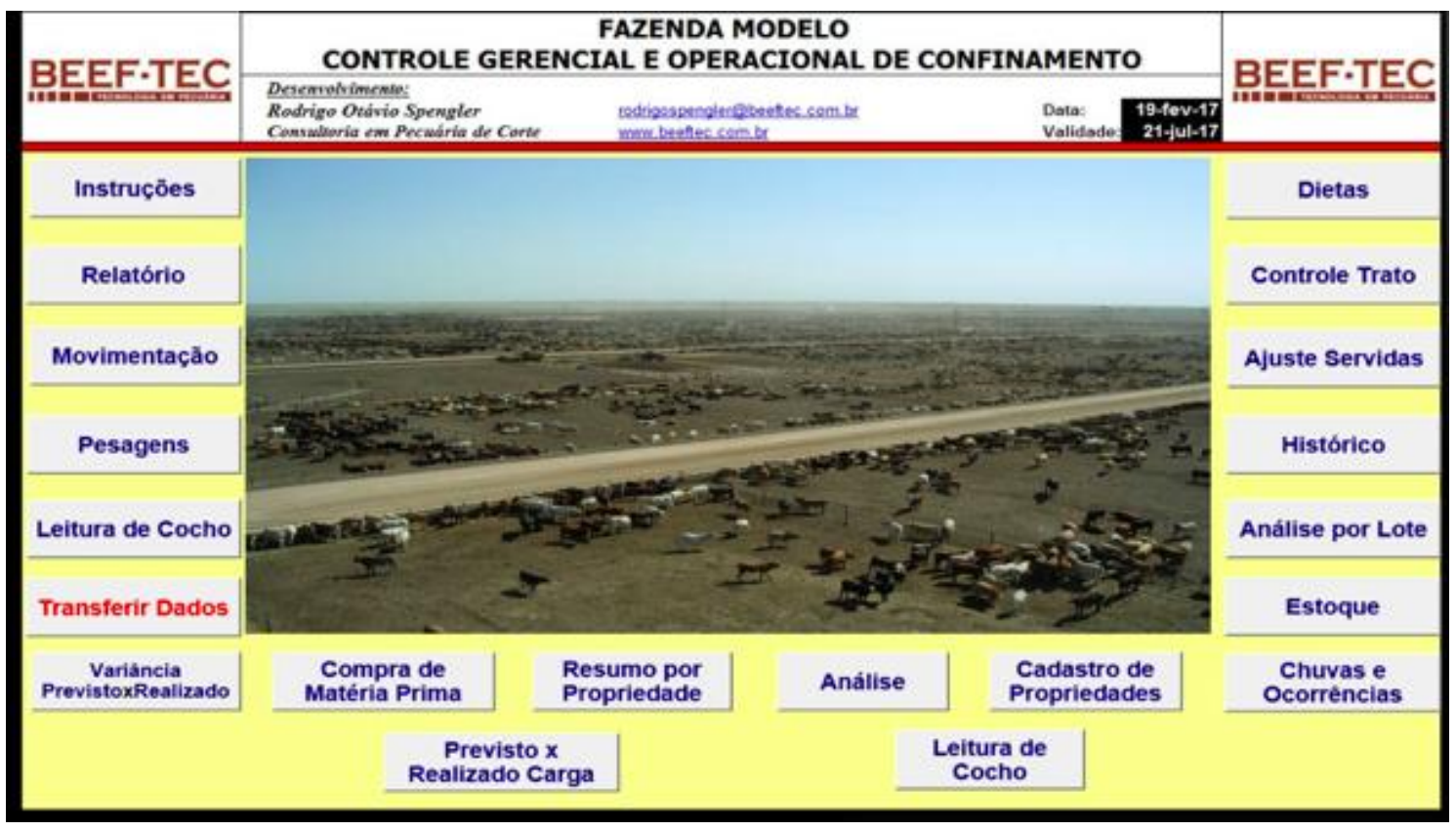

Fonte: Beeftec, 2020.

O que ocorre é que as propriedades com baixa taxa de retorno, tendem a perder na competição com o grande empreendimento agroindustrial moderno. As fazendas de pecuária extensiva tendem a se modernizar para se manterem competitivas, presentes no mercado.

\section{Considerações Finais}

A dinâmica produtiva da pecuária bovina no Estado de Mato Grosso do Sul é resultado de uma combinação de recursos humanos, técnicos, físicos, de capital e financeiros, com destaque para a disponibilidade de recursos que conferem vantagens comparativas naturais, além da estrutura fundiária favorável à pecuária extensiva. A concentração do rebanho ocorre nos municípios pantaneiros e na porção oeste do estado, que ao longo dos anos conseguiu fechar o ciclo de cria, recria e engorda.

A atividade tem se modernizado, se valendo dessa combinação eficiente de recursos cujo acúmulo de expertise, permitiu inserção no mercado internacional, via exportações tanto de carne congelada e refrigerada, por meio de frigoríficos internacionalizados, quanto de genética, com a venda do boi em pé, demonstrando tanto produtividade quanto competitividade. 
A competitividade é um fator que pode ser colocado em risco caso as políticas de sustentabilidade não sejam suficientemente atendidas. Mercados consumidores exigentes podem encontrar novos fornecedores se avaliarem que as condições da cadeia produtiva são geradoras de externalidades negativas (tipo avanço em áreas de reservas naturais, aumento do desmatamento, aumento da emissão de carbono, queimadas e redução da biodiversidade, emprego de trabalho análogo à escravidão, conflitos com populações em condições de vulnerabilidade social). Há uma competitividade sempre provisória, mantida se mantidas as exigências de mercado, inclusive as que se desenvolvem no jogo da geopolítica do comércio internacional.

Por fim, a pecuária, enquanto atividade econômica comercial, como as demais, visa obtenção de lucros e, como tal, também é geradora de conflitos socioambientais em várias escalas. Embora não tenham sido objeto de reflexão, dado o escopo delimitado por este texto, esperamos que as informações e reflexões aqui apresentadas possam servir de subsídios à continuidade do desafio que é compreender a dinâmica produtiva da pecuária bovina no espaço geográfico brasileiro.

\section{Agradecimentos}

A autora agradece ao CNPq pela Bolsa de Produtividade em Pesquisa 2.

\section{REFERÊNCIAS}

BENITEZ, Miguel Gimenez. Brasil Central Pecuário: interesses e conflitos. São Paulo : Editora da Unesp, 2000.

BERNARDES, Julia Adão; CASTILLO, Ricardo (org.). Espaço geográfico e competitividade: regionalização do setor sucroenergético no Brasil. 1ed. Rio de Janeiro : Lamparina, 2019.

BERTHOLI, Anderson. O lugar da pecuária na Formação Socioespacial Sulmatogrossense. 2006. Dissertação (Mestrado em Geografia). Universidade Federal de Santa Catarina, Florianópolis, 2006.

CASTILLO, Ricardo. Dinâmicas recentes do setor sucroenergético no Brasil: competitividade regional e expansão para o bioma Cerrado. GEOgraphhia, Niterói, n.32, p. 95-119, 2015.

CHOLLEY, André. Observações sobre alguns pontos de vista geográficos (1a parte). Boletim Geográfico. n. 179. p.139-145, 1964a. . Observações sobre alguns pontos de vista geográficos (2a parte). 
Boletim Geográfico. n. 179. p.268-277, 1964b.

EMBRAPA/BOLETIM CICARNE. A produtividade do rebanho brasileiro em carcaças aumentou $80 \%$ em vinte anos. Boletim Embrapa/CiCarne, 2020. Disponível em

https://www.embrapa.br/documents/1355108/51748908/Boletim+CiCarne+008.pdf/24c d5724-0ab7-3760-0f27-3120a54ec622. Acesso em 12 mai. 2020.

FARIA, Elaine dos Santos; MASSOCA, Geraldo Magela; JOSÉ, Jozenildo. A piscicultura como alternativa de diversificação econômica para os produtores do município de Dourados-MS. Monografia (Bacharelado em Geografia). Centro Universitário de Dourados, Universidade Federal de Mato Grosso do Sul, 1999.

GALERA, Mauricio Martorelli. A inserção dos frigoríficos exportadores de Mato Grosso do Sul no mercado global. 2011. Dissertação (Mestrado em Geografia) Faculdade de Ciências Humanas, Universidade Federal da Grande Dourados, DouradosMS, 2011.

GIRARDI, Eduardo Paulon. Atlas da questão agrária brasileira, 2008. [s/ed]. Disponível em http://www.atlasbrasilagrario.com.br/con_subcat/estrutura-fundiaria. Acesso em 4 nov. 2020.

IBGE. Censo Agropecuário. Rio de Janeiro : IBGE, 2018. Disponível em: https://censos.ibge.gov.br/agro/2017/. Acesso em: 8 de jan. 2020.

Produção agrícola municipal. IBGE, 2020. Disponível em https://sidra.ibge.gov.br/. Acesso em: 3 nov. 2020.

LAMOSO, Lisandra Pereira; FERREIRA, Alice; CORONEL, Adriana; STRAUB, Tatiana. A expansão da suinocultura na porção meridional do Estado de Mato Grosso do Sul. Revista de Geografia (UFMS), Dourados-MS, v. 1, n.2, p. 26-34, 1996.

LAMOSO, Lisandra Pereira; SILVA, Walter Guedes da. O complexo agroindustrial da suinocultura no município de Dourados-MS. Revista de Geografia (UFMS), Campo Grande-MS, v. 1, n.1, p. 31-38, 1997.

LIMA, Valdomiro de Oliveira. A indústria frigorífica de Mato Grosso do Sul: entre grupos internacionalizados e as unidades voltadas ao mercado interno. 2018. Dissertação (Mestrado em Geografia) - Universidade Federal da Grande Dourados.

MAMIGONIAN, Armen. Inserção de Mato Grosso ao Mercado Nacional e a Gênese de Corumbá. GEOSUL, nº $1.1^{\circ}$ semestre, 1986.

Notas sobre os frigoríficos do Brasil Central Pecuário. Boletim Paulista de Geografia, nº 51. São Paulo: AGB, 1976.

MANFRÉ, Éder; SPÍNOLA, Silvia Cristina; LIMA, Vanderly Pedro de. A helicicultura no município de Caarapó-MS: alternativa de diversificação econômica. 
Monografia (Bacharelado em Geografia). Centro Universitário de Dourados, Universidade Federal de Mato Grosso do Sul, 1999.

MAPA. Ministério da Agricultura, Pecuária e Abastecimento. Disponível em: https://www.gov.br/agricultura/pt-br . Acesso em: 13 mai 2020.

PAZ, Patrícia Pogliesi da. A inserção das exportações de carne bovina sulmatogrossense no mercado internacional. Monografia (Bacharelado em Geografia). Centro Universitário de Dourados, Universidade Federal de Mato Grosso do Sul, 2009.

SANCHÉZ, Joan-Eugeni. Espacio, economia y sociedade. Madrid : Siglo Veinteuno, 1991.

SANTOS, Milton. A natureza do espaço: técnica e tempo, razão e emoção. São Paulo, Hucitec, 1996.

Por uma geografia nova. 3ed. São Paulo : Hucitec, 1990.

SEMAGRO. Rebanho bovino de Mato Grosso do Sul cresce e já supera 21,8 milhões de cabeças. Disponível em http://www.semagro.ms.gov.br/rebanho-bovino-de-ms-crescee-ja-supera-218-milhoes-de-cabecas/. Acesso em: 12 mai. 2020.

SILVESTRE, Elisa de Avila; GUERINI, Isa Maria Formaggio Marques. A pecuária como determinante econômico da ocupação de Campo Grande, Mato Grosso do Sul: 1870 a 1929. Albuquerque - Revista de História. vol. 6, n. 12. jul.-dez./2014, p. 31-53. 